\title{
Analysis of Retention Time and Steam Pressure Variations in the Conditioning Process on the Moisture Content of Feed in the Packaging Process
}

\author{
Rivai Suhendra $\mathrm{F}^{\mathbf{1}} \mathbf{8}(\mathrm{D}) \square$ and Isdaryanto Iskandar ${ }^{\mathbf{2}} \mathbf{\mathrm { B }}(\mathrm{D}$, \\ ${ }^{1}$ Faculty of Engineering, Atma Jaya Catholic Universityof Indonesia, Jendral Sudirman St Kav 51, Jakarta 12930, Indonesia \\ ${ }^{2}$ Faculty of Engineering, Atma Jaya Catholic Universityof Indonesia, Jendral Sudirman St Kav 51, Jakarta 12930, Indonesia \\ $\checkmark$ Corresponding Author: Rivai Suhendra F, E-mail: rivaisuhendraf@gmail.com
}

\begin{tabular}{|c|c|}
\hline ARTICLE INFORMATION & ABSTRACT \\
\hline Received: August 08, 2021 & Pellets are compressed feed, compacted through a mechanical process. Pellets can be \\
\hline Accepted: October 03, 2021 & molded in the form of lumps and small cylinders with different diameters, lengths, and \\
\hline Volume: 2 & levels of strength. The right moisture content value will maximize the quality of the \\
\hline Issue: 2 & pellets and increase the value of the Pellet Durability Index(PDI). Many factors affect \\
\hline DOI: 10.32996/jmcie.2021.2.2.1 & $\begin{array}{l}\text { the moisture content in the feed such as changing the steam pressure configuration, } \\
\text { adding moisture to the mixing process, changing the retention time configuration, and }\end{array}$ \\
\hline KEYWORDS & other methods. The method tested was to provide variations on the configuration of \\
\hline $\begin{array}{l}\text { Pellet; Retention time; Steam } \\
\text { pressure; Feed moisture content }\end{array}$ & $\begin{array}{l}\text { retention time and steam pressure on the Pressure Reducing Valve (PRV) which aims } \\
\text { to determine the increase in moisture content in the feed. Variations of retention time } \\
\text { configuration tested were } 50 \text { seconds, } 55 \text { seconds, } 60 \text { seconds, } 65 \text { seconds, } 70 \text { seconds } \\
\text { with variations in the Steam pressure configuration in the test were } 1.4 \text { bar and } 1.6 \text { bar. } \\
\text { The test results prove that the retention time of } 65 \text { seconds with a steam pressure of } \\
1.4 \text { bar is the best configuration with an increase in moisture content of } 2.67 \% \text { with a } \\
\text { difference in moisture content of bagging to the mixing of }-0.46 \text {. }\end{array}$ \\
\hline
\end{tabular}

\section{Introduction}

Pelleted feed is compressed feed, compacted through a mechanical process. The pelleted feed can be molded in the form of lumps and small cylinders of different diameters, lengths, and levels of strength (Ensminger M. E., Oldfield J. E., 1990). The pelleted feed has the benefit to facilitate feed handling and improving livestock performance. Pelleting increases density and flowability prevent feed from being scattered and blown away by the wind and increases feed conversion. Improved performance occurs due to increased digestibility, decreased separation of ration ingredients, less energy to digest feed, and increased palatability (Behnke, 1998).

The pelleting process consists of several processes such as the process of filling raw materials, grinding, mixing, conditioning (usually by a steaming process), molding, and cooling (Abdollahi, M.R., Ravindran, V., Svihus, 2013). Moisture content is one of the most important components in the pelleted feed. The right moisture content value will maximize the quality of the pellets and increase the value of the Pellet Durability Index(PDI). Pelleted feed PDI value for broiler chickens is a minimum of $80 \%$ (Dozier, 2001) with the moisture content of the feed during the packaging process (bagging) equivalent to the moisture content in the mixing process up to a maximum of $11.5 \%$ of the total weight of feed in one sack (50 kilograms).

The addition of the moisture content of the feed occurs in the conditioning process when steam is injected into the conditioner machine with feed continuously stirred by the pedal, while the process of reducing the moisture content of the feed occurs in the cooling process.



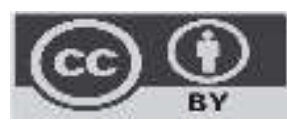

Published by Al-Kindi Center for Research and Development. Copyright (c) the author(s). This open access article is distributed under a Creative Commons Attribution (CC-BY) 4.0 license 
The following table is the feed moisture content after the mixing process, adding moisture content in the conditioning process, and reducing moisture content in the cooling process, taken from audit data on pelleted feed moisture content in a company during the period from February to April 2021.

\begin{tabular}{|l|l|l|}
\hline Month & Conditioning & Bagging \\
\hline \multirow{4}{*}{ Jan } & 0.83 & -2.15 \\
\cline { 2 - 3 } & 1.28 & -1.92 \\
\cline { 2 - 3 } & 1.43 & -1.91 \\
\hline \multirow{4}{*}{ Feb } & 1.13 & -1.81 \\
\cline { 2 - 3 } & 1.32 & -1.73 \\
\cline { 2 - 3 } & 1.76 & -1.99 \\
\hline \multirow{4}{*}{ Mar } & 1.14 & -1.75 \\
\cline { 2 - 3 } & 1.29 & -1.85 \\
\hline \multirow{2}{*}{ Average } & 1.33 & -2.29 \\
\hline
\end{tabular}

Table 1. The amount of moisture content of the pelleted feed after the raw material mixing process

Adding moisture content in the conditioning process was still not optimal in which the average was $1.03 \%$. This causes low moisture content in the packaging process (bagging) with the average moisture content of the feed reduced by $1.93 \%$ of the moisture content in the mixing process.

There are several methods that can be used to increase the moisture content of the feed, including:

a. Adding water to the mixing process

b. Adding water to the conditioning process

c. Regulating steam pressure in the conditioning process

d. Set the retention time in the conditioning process.

Adding water in the mixing and conditioning process will cause the feed to be lumpy and sticky in the mixer and conditioner machines. In addition, it is necessary to modify the mixer and conditioner machines so that they can change the initial design of the machines which can reduce the machine performance. Modifications will cause additional costs which add to the cost of production.

The easiest method that might be done is to change the configuration of retention time and steam pressure in the conditioning process because the treatment can be completed without having to install additional equipment or change the characteristics of the feed.

In this regard, the author is interested to test the method related to "Analysis of Retention Time and Steam Pressure Variations in the Conditioning Process on the Moisture Content of Feed in the Packaging Process". 


\section{Research Methods}

\subsection{Research Setting}

The research was conducted at PT Malindo Feedmill Tbk in April 2021.

\subsection{Pellet Making Process}

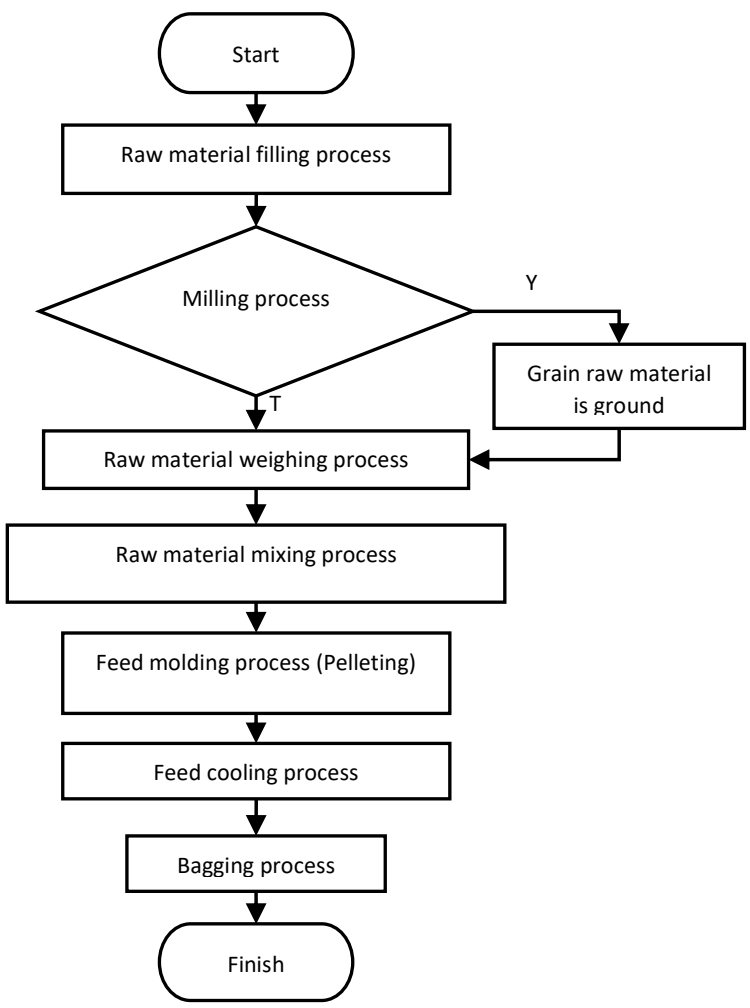

Figure 1. Pelleted Feed Making Flowchart

The raw materials were mixed on the mixer machine by adding prefix and liquid. The mixed raw materials were then distributed to the pellet machine for molding. In the molding process, the feed entered into the conditioner to be cooked using steam which also increased the moisture content of the feed. The feed was then molded using rolls and dies. The molded feed was cooled to reach room temperature, which was then packaged and stored in the Finish Good Warehouse.

\subsection{The Process of Adding Moisture Content}

Adding moisture content was done by changing the initial retention time and steam pressure configuration of the Pelletmill Buhler Machine type DPHD-660/DPHE-900 at PTMalindoFeedmillTbk at a steam pressure of 1.6 bar after Pressure Reducing Valve (PRV) with a retention time of 55 seconds.

Retention time is the length of time the feed raw material is exposed to steam which is related to the capacity of the conditioner, the rotational speed of the bearing, and the slope of the pedal conditioner. The retention time used in the test was 50 seconds, 55 seconds, 60 seconds, 65 seconds, 70 seconds.



Figure 2. Illustration of the effect of retention time on steam penetration in conditioner (Sukarman, 2010). 
The right retention time can make steam evenly distributed throughout the raw materials as shown in Figure 2 . If the speed is too low then the steam will not mix with the raw materials, but if the bearing speed is too fast then the raw materials will be on the edge of the conditioner while the steam will be in the middle. As a result, steam and raw materials are not mixed evenly and the gelatinization process will not be perfect (SpiraxSarco, 2021).

Meanwhile, the steam configuration on the PRV used was 1.6 bar and 1.4 bar. The steam pressure of 1.6 barwas the initial configuration of the pellet machine, in which the steam pressure reaching the conditioner was 1 bar and had a temperature of $110-120^{\circ} \mathrm{C}$ (Table 2). At 1 bar pressure, the saturated steam volume was $0.881 \mathrm{~m} 3 / \mathrm{kg}$.

\begin{tabular}{|c|c|c|c|c|c|}
\hline \multirow{2}{*}{$\begin{array}{l}\text { Gauge } \\
\text { Pressur } \\
\text { e } \\
\text { (bar) }\end{array}$} & \multirow{2}{*}{$\begin{array}{l}\text { Tem } \\
\mathbf{p} \\
\left(C^{\circ}\right)\end{array}$} & \multicolumn{3}{|c|}{ Enthalpy in $\mathrm{kJ} / \mathrm{Kg}$} & \multirow{2}{*}{$\begin{array}{l}\text { Volume } \\
\text { Dry } \\
\text { Saturat } \\
\text { ed } \\
\left(\mathrm{m}^{3} / \mathrm{kg}\right)\end{array}$} \\
\hline & & $\begin{array}{l}\text { Water } \\
\left(h_{f}\right)\end{array}$ & $\begin{array}{l}\text { Evap } \\
\left(h_{\mathrm{fg}}\right)\end{array}$ & $\begin{array}{l}\text { Stea } \\
\mathrm{m} \\
\left(\mathrm{h}_{\mathrm{g}}\right)\end{array}$ & \\
\hline 0 & 100 & 419 & 2257 & 2676 & 1.673 \\
\hline 1 & 120 & 506 & 2201 & 2707 & 0.881 \\
\hline 2 & 134 & 562 & 2163 & 2725 & 0.603 \\
\hline 5 & 159 & 671 & 2086 & 2757 & 0.315 \\
\hline 7 & 170 & 721 & 2048 & 2769 & 0.24 \\
\hline 10 & 184 & 782 & 2000 & 2782 & 0.177 \\
\hline 14 & 194 & 845 & 1947 & 2792 & 0.132 \\
\hline
\end{tabular}

Table 2. Part of the saturated steam table

This indicates that the steam content in the conditioner is still quite high, and the steam will only reach a phase change. The phase change occurs at a temperature of $100^{\circ} \mathrm{C}$ (Figure 3).

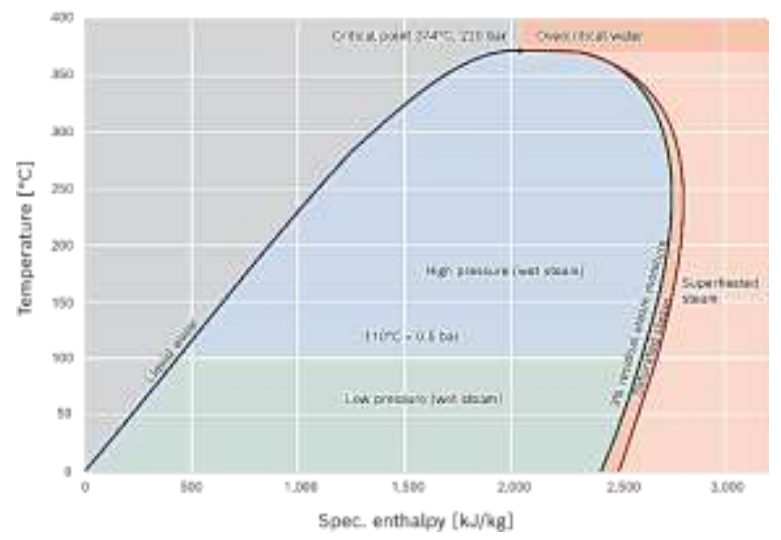

Figure 3. Change of Moisture Phase in T-h diagram

Based on this, in the second experiment, the configuration of the steam pressure on the PRV was reduced to 1.4 bar. This was done to reduce the steam pressure when it goes to the conditioner so that the steam pressure during the conditioning process is close to 0 bar and the temperature is $100^{\circ} \mathrm{C}$ which is a condition where the steam changes phase. This is expected to increase the moisture content of the feed.

\subsection{Tools and materials}

In this research, measuring tools that were prepared in the data collection process is as follows:

1. Digital scales function as a measuring tool to determine changes in the mass of the sample used

2. The stopwatch functions as a time-measuring device in data collection.

3. The cup serves as a container for feed samples that have been taken and will be in the oven.

4. The thermometer functions as a tool to measure the feed temperature and the room temperature of the Pellet Machine.

5. Ovens are used for heating, baking, or drying an ingredient, and are generally used for cooking. 
The material used as a sample is feed with the trademark 8202 OM in which 8202 OM feed is the main commodity of Pelleted Feed at PT MalindoFeedmillTbk. The purpose of selecting feed $8202 \mathrm{OM}$ is to avoid significant differences in the formula so that the test results do not vary and are maximal.

\subsection{Testing Steps}

The test steps are as follows:

1. Prepare the tools needed to conduct research.

2. Weigh the empty cup and record it.

3. Operate the Pellet Machine until the Pellet Machine operates in optimum conditions, namely the temperature in the Pellet Conditioner is $81^{\circ} \mathrm{C}$ with a capacity rate of 18.6 tons/hour.

4. Take samples from the Pellet Bin, feed after the Conditioner Pellet Machine process, and feed that has been molded.

5. Cool the feed sample to room temperature.

6. The sample that has been taken is then poured into a cup, then weighed with a sample weight not exceeding 2.0099 grams.

7. Then heat the cup containing the sample in the oven for 2 hours at a temperature of $135^{\circ} \mathrm{C}$.

8. Cool the cup in a desiccator for 25 minutes.

9. Then weigh the cup and record the results of the scales and calculate the shrinkage that occurs.

10. Repeat the above steps for other test variations.

\section{Results and Discussion}

The test is done by combining the retention time treatment with the steam pressure configuration. The first test was carried out with a steam pressure of 1.6 bar and a retention time configuration of 50 seconds, 55 seconds, 60 seconds, 65 seconds, 70 seconds and for the second test, the steam pressure was changed to 1.4 bar with the same retention time configuration at a pressure of 1.6 bar. The test was repeated three times for each test and the test results were averaged to determine the value of adding moisture content. The analysis was done by looking at how changes in moisture content occurred due to differences in the treatment given. The changes were then inputted into the graph to see the changes in moisture content:

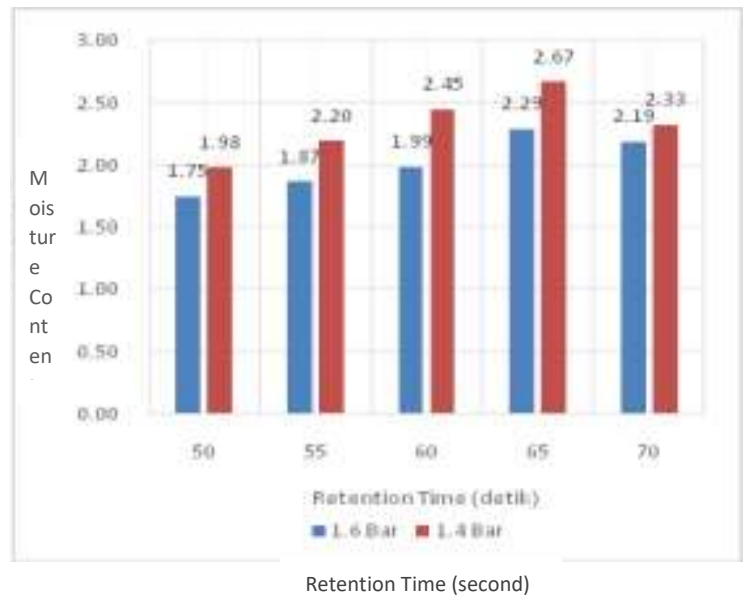

Figure 4 Graph of adding moisture content in the conditioning process with a steam pressure of 1.6 bar and 1.4 bar

In the graph (Figure 4), it is known that there is an effect between changes in the configuration of steam pressure and retention time on increasing the moisture content of the feed. The lowest increase in moisture content occurred at retention time for 50 seconds, specifically $1.75 \%$ at a pressure of 1.6 bar and $1.98 \%$ at a pressure of 1.4 bar, while the highest increase in moisture content occurred in the retention time configuration for 65 seconds with an increase of $2.29 \%$ at 1.6 bar pressure and $2.67 \%$ at 1.4 bar pressure.

This is because the right retention time can make steam evenly distributed throughout the raw materials. At a retention time of 50 seconds, the pedal conditioner stirs the feed too fast so that some of the feed is on the edge of the conditioner, while the steam will be in the middle. As a result, steam and raw materials are not mixed evenly and reduce the moisture content of the feed.

However, the long retention time is not directly proportional to the moisture content of the feed. The increase in moisture content at a retention time of 65 seconds is better than the retention time of 70 seconds, both with a steam pressure of 1.6 bar and 1.4 bar. This is because the pedal stirs the feed for too long so that only part of the feed is mixed with the steam, and some accumulate 
at the bottom of the conditioner so that the moisture absorption becomes excessive in some of the feed. This causes the conditioner to slip and can damage the pellet machine.

Steam pressure configuration also influences increasing moisture content. In the graph (Figure 4), the same retention time configuration with different steam pressure configurations results in different increases in moisture content. Steam pressure at 1.4 bar provides a better increase in moisture content compared to a steam pressure of 1.6 bar. This proves that at a pressure of 1.4 bar steam has reached the phase change stage. Therefore, the moisture content going to the conditioner increases. This increase contributes to increasing the moisture content of the feed.

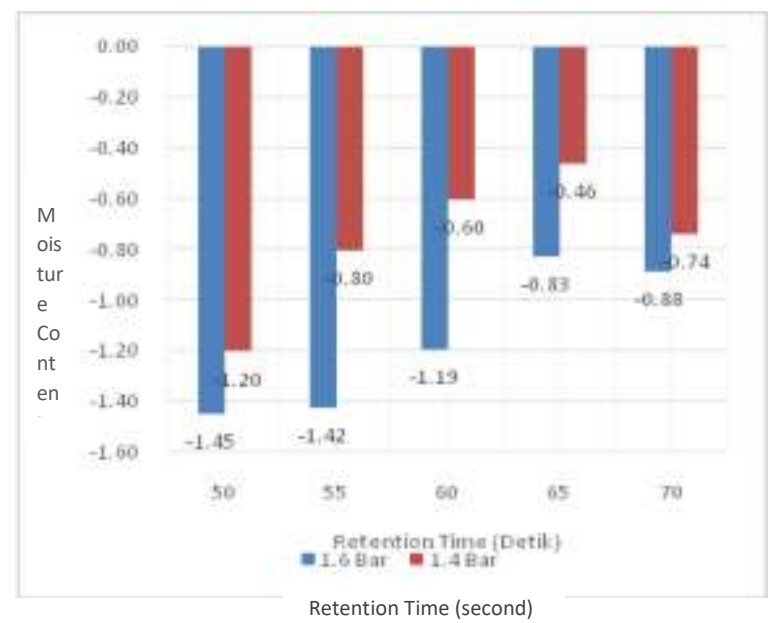

Figure 5 Graph of the difference in moisture content in the bagging process to the moisture content in the mixing process

The increase in the moisture content of the feed also has an impact on the moisture content of the feed in the bagging process. It can be seen in the graph that there is a decrease in the difference between the moisture content in the bagging process and the moisture content in the mixing process, where the lowest difference occurs at the retention time of 65 seconds with a steam pressure of 1.4 bar, which is $-0.46 \%$.

This happens because, during the cooling process of feed, the feed has a temperature ranging from $80^{\circ} \mathrm{C}-90^{\circ} \mathrm{C}$, so that the process of evaporation of moisture content in the feed occurs until it reaches room temperature. With the high moisture content in the feed, the difference between the moisture content in the bagging process and the moisture content in the mixing process is reduced.

\section{Conclusion}

Based on the research results and discussion, it is concluded that the configuration of retention time and steam pressure affected the increase in moisture content in the feed. The highest increase in feed moisture content was found in the retention time test for 65 seconds with a steam pressure of 1.4 bar, specifically $2.67 \%$ with a difference in bagging moisture content against the mixing of $-0.46 \%$. This is caused by an earlier condensation process on the steam pipeline leading to the conditioner so that the volume of moisture in the conditioner increases accompanied by the time of mixing the feed in the right conditioner so that the absorption of moisture in the feed is maximal and increases the moisture content of the resulting feed and reduces the decrease the amount of moisture content in the bin bagging.

\section{References}

[1] Abdollahi, M.R., Ravindran,V., Svihus, B. (2013). Pelleting of broiler diets: An overview with emphasis on pellet quality and nutritional value. Animal Feed Science and Technology, 179 (2019), 1-23

[2] Behnke, K. C. (1998). Why Pellet? Proceedings Kansas State University/American Feed Industry Assoc.

[3] Dozier, W. A. (2001). Pellet quality for more economical poultry meat. Journal Feed International., 52 (2), 40-42.

[4] Ensminger M. E., Oldfield J. E., and W. W. H. (1990). Feed and Nutrition (2nd Editio). The Ensminger Publishing Company.

[5] SpiraxSarco. (2021). Steam Engineering Principles And Heat Transfer. 19, 52. https://www.spiraxsarco.com/learn-about-steam/steamengineering-principles-and-heat-transfer/what-is-steam

[6] Sukarman, S. (2010). STEAM DALAM PEMBUATAN PAKAN UNTUK KOMODITAS AKUAKULTUR. Media Akuakultur, 5(2), $123-128$. 